\title{
Corporate social responsibility in Russia
}

\author{
Elena Zavyalova*, and Elena Ostrovskaya \\ Moscow State Institute for International Relations (MGIMO University), Prospect Vernadskogo, 76, \\ 119454 Moscow, Russia
}

\begin{abstract}
Nowadays companies try to strike a balance between maximizing their profit and being socially responsible. On the one hand, a lot of scientists and economists admit that the primary goal for any company has been and still is to maximize profits of shareholders. On the other hand, some other experts believe that a company nowadays should not concentrate only on pursing profits. Some other objectives are connected with interests of stakeholders, ethical and moral behavior of a company and others. Based on the analysis of theoretical approaches, the paper offers to unify different groups and their interests and goals. The authors during the research come to the conclusion that the development of CSR in Russia is directly connected with the country's peculiarities and at the same time all European best practices are taken into consideration and relied upon by Russian companies in terms of CSR.
\end{abstract}

\section{Introduction}

The idea that companies should be socially responsible for their activities appeared in the 20 century, but such ideas have become widespread and have been introduced into companies' everyday practice since the beginning of the 21 century. Large multinational companies admit that lives of millions of people all over the world depend on these companies' activities. Moreover, these companies have an impact on the economic and political climate of the countries where they operate.

Every time when there are debates about social responsibility of business, a question arises concerning the role and place of business in real social and economic conditions of a certain country. We may suppose that the level of involvement of any business in social problems mostly depend on the political and economic system in a certain country, and this system imposes typical norms of ethical behavior, especially in business. So, socialist background proves that the development of CSR is similar in former Soviet countries (Kazakhstan) and BRICS countries, such as China, i.e. CSR is developing fast in large corporations, which were founded during the Soviet period, and is developing at a much smaller pace in small and medium-sized business.

The authors prove that in Russia CSR is gaining ground. The majority of Russian scientists and experts in this field admit this fact. CSR programs are mainly introduced by industrial giants in accordance with the world practice, but have a number of peculiarities, connected with Soviet background of these companies.

\footnotetext{
${ }^{*}$ Corresponding author : e.zavyalova@inno.mgimo.ru
} 


\section{Materials and Methods}

The presented analysis is based on the concept of the stakeholder theory. Using the methods of inductive and deductive approach, general-purpose approach, namely the comparative analysis: synthesis, generalization, classification, systematic and institutional approaches, as well as statistical analysis we will analyze both theoretical basis and practical implementations in Russia.

This theory implies that any business should not concentrate only on maximizing profits for its shareholders, but it should also serve interests of different stakeholders. So the idea runs as follows: aims of a corporation are connected with interests of other groups apart from shareholders.

\section{Results and Discussions}

In May 2018, a new executive order on national goals and strategic objectives through to 2024 was announced, and the primary goal is socially oriented growth. It is obvious that the huge volume of social entitlements from the budget is required, and the government cannot cope with this task alone, that is why there is a primary objective to attract business to help the authorities with social issues. Especially it is worth doing in such spheres that may enhance competitiveness of the business: education, healthcare, all types of internal CSR.

The modern situation has its roots deep in the Russian history. Social ideas have always been very popular. In the nineteenth century, for instance, representatives of the big business supported artists, musicians or founded hospitals or orphanages. They were known as "maecenas" and the Russian society still enjoys some of their deeds. The most famous are the Russian railways built by the Morozovs and Tretyakov Art Gallery. After the revolution in 1917 the whole policy was socially oriented, though it was more like the state requirement and not a voluntary company initiative. But now in modern Russia the attitude of the different social layers to corporate social responsibility is controversial.

In general, the term CSR cannot be applicable to those companies, which existed during the USSR period, since CSR is the occurrence of the market economy; moreover, it is the voluntary decision of a company that is pursuing its market goals. There was not such a term as CSR in the USSR.

However, the USSR really provided its citizens with social guarantees and in many cases people's welfare depended largely on the company where they used to work. There was such a term as "concern for demands of workers". Soviet enterprises were responsible for providing their workers with accommodation, food, healthcare, organizing their leisure time and rest. The enterprises owned houses where their workers used to live, hospitals, kids' summer camps, rest houses, cultural centers, etc. Such "benefits" were available both to workers of the enterprise, and to city dwellers of nearby territories.

According to the statistics, by 198032 million people had lived in apartments that were owned by enterprises, 30 million people had used healthcare, and 1.5 million kids had spent their vacations in summer camps that belonged to enterprises.

We should start analyzing the issue with the statement that there is no unified approach, in the Russian scientific or in the business society. The most common approach appeared in the 90 -s. That time can be characterized as an initial capital accumulation period. It means that the main task of the business is seen only as getting maximum profit. According to this approach corporate social responsibility (CSR) is associated with the following pattern. An efficient company develops successfully constantly increasing the volume of its activity. It leads to the creation of new working places, which in turn leads to the increase in the social welfare. So, this approach to corporate social responsibility is similar to the classical concept of the "corporate egoism". This point of view is still popular, though it is quite 
different from the modern perception of CSR in the world leading economies, namely the EU countries or the USA.

However, today in the modern Russian society there is a clear shift to the "corporate altruism" theory. According to the theory companies are expected to finance socially important programs voluntary limiting their potential profits. The Russian society gradually starts to understand that corporate social responsibility is not just charity or vise a versa profit optimization (Aßländer\&Curbach, 2017). Corporate social responsibility can be characterized as a mutually beneficial development strategy of the company and its surroundings. Any company that voluntary invests in the social sphere becomes a "good partner" that leads to the profit increase in the long run. If this attitude to CSR prevails, the Russian approach will be quite similar to the definition given by the European Commission "the responsibility of enterprises for their impacts on society". (European Commission)

This difficulty in finding the consensus in the definition in Russian reality can be mainly explained by the fact that the state, business and the Russian society have extremely different expectations of the socially oriented programs.

We shall start our analysis with the Russian business. Relatively young Russian business is accustomed to working in rather tough conditions. It means that business has to accumulate all resources to survive, not to mention the increase in volume and quality of production. It took more than 20 years for the Russian business to realize the necessity and "profitability" of CSR. The numerous surveys done by different public organizations [17, 13], show that businessmen see their CSR more as a responsibility first of all for their shareholders and employees. They agree to meet the requirements of the local community or to finance some socially or ecologically oriented programs on the state level only if there are some extra resources left. Another specific feature is that corporate social programs are more feasible when they are conducted by strategically oriented companies, mostly having tight connections with the state.

It is also important to mention that the country has been pursuing the liberal economic policy for more than twenty years. The classical understanding of the liberal policy logic implements that social responsibility of any company can be measured by tax payments and creation of new working places.

All this led to two major ways of understanding CSR by Russian business. CSR is divided in external and internal. The internal one is more popular with the modern Russian businessmen especially from the small and medium sized segment. It includes all forms of staff programs: from creation and maintenance of the social infrastructure to creation of the good family like psychological climate at the working place.

External CSR programs usually focus on the creation of a company's positive image. It is even more important when the company decides to enter foreign markets. Another frequent direction of the external CSR of Russian companies is the minimization of the tension with the municipal authorities and the local communities.

To make the picture of the Russian business mentality complete, we need to see the difference between small and big business attitude. If in Europe and other developed countries the small and medium-sized business is an active and significant player in the national economy, which participates in different economic activities, including CSR programs, then in Russia SME (small and medium-sized enterprises) account for only 12 per cent of the GDP. It means that even if they become interested in the development of the CSR programs and achieve some results it is not that visible compared to the big business activities.

So, it can be stated that CSR is the sphere for the Russian big business, and the situation is not likely to change in the near future. There are some reasons for this. First of all, only big business has additional financial resources that can be spent on socially oriented programs. Secondly, the big business is more involved in the state socially oriented 
projects. And the last reason is that the big business is much more concerned with the maintenance of the social (and political) stability and is ready to pay for it.

The Russian society has quite the opposite position.

By the waning years of the Soviet period, people were used to the fact that social guarantees provided by the government were an integral part of their life. So when the situation in the country changed dramatically and the market economy replaced the Soviet planned economy, and as a result huge social inequality and making everything commercial (that used to be provided free of charge and was guaranteed to any person), made people think that they were cheated and insulted.

The most popular point of view is the following. During the privatization period (in the 90 -s) the business got extra huge assets, so now they are responsible for the poor population which still feels like being robbed or deprived due to the liberal reforms. Social policy of a company, which became not a responsibility, but a voluntary decision of the board of the company, is treated by the majority of people as money laundering.

In some cases, it can be seen even as a kind of public pressure on the company, especially if a company's history goes back to the soviet past. The owners of such companies have to pay more attention to the social programs, especially external ones.

There is another controversial point of view in the Russian society. It is quite frequent when the active philanthropic activity of a company, even when it has a clear socially oriented goal, is seen by ordinary people as a way of laundering money. It will take a lot of time and effort to change the attitude. Such efforts should ensure, first of all, higher transparency of CSR programs to increase mutual trust.

The tendency is even more evident in small cities, where the majority of the population works for one company (in Russia such cities are called "monotowns").

In Russia, there are nowadays at least 319 monotowns. These towns are built around one or several enterprises that are linked by a line of production. All the infrastructure of this town is aimed at providing continuous operation of such a city-forming enterprise in the monotown. During the privatization process the enterprise was not supposed to take care of city life. Still there was an open question connected with the future of people living in such a city. So the enterprise was forced to take care of its workers, infrastructure and ecology of the city. Such cities became real leaders of CSR in Russia. Successful development of towns where these enterprises operate is directly linked with the success of the enterprise. That is why there are even depressed regions (around 149). These monotowns and their city-forming enterprises need state support in order to preserve and improve social and economic welfare of citizens.

An excellent example of such a monotown in Russia is Magnitogorsk, which was founded around joint-stock company Magnitogorsk Iron and Steel Works (MISW or MMK). MMK is an example of a fast-growing business today; its shares have been traded on the London Stock Exchange since 2007.

As the management of MMK states CSR is the most important principle of its work. CSR of the company includes creating effective and safe working places, professional staff development, support of cultural programs and sport events, environmental protection, multi-level system of healthcare, helping to develop the regions where it operates. Building hospitals, schools, roads and houses, maintaining at a certain level cultural centers, rest houses and kids' summer camps, creating a number of events aimed at improving lives of citizens of Magnitogorsk is the achievement of MMK.

The efficiency of CSR depends not only on companies' and the society perception. One of the most important factors is the state attitude to the issue. In the ideal model, the role of the state should be limited to the creation of the necessary framework and encouragement of business to launch and support social projects (Aßländer\&Curbach, 2017). Unfortunately, in the real Russian everyday life the government interference in the 
corporate social activity looks more like an ultimatum. It undermines the main principle of CSR - its voluntary nature. The state doesn't only push the business to CSR (which is good, since it gives quite strong impulse to business to launch some socially important programs), but more often than that the government also points out the main spheres for CSR (which is bad as the companies might have some other priorities). As a result state initiated CSR projects have limited efficiency and look more like a show off. Although some experts believe that, CSR should not always be voluntary decisions of corporations, but the initiatives in CSR introduced by the state will be more effective rather than voluntary activity of corporations (Brejnholt et al. 2019). For instance, such a scheme is used in China, where the government persuades companies to take part in state programs to eradicate poverty, improve educate, etc. (Hofman, Moon, \& Wu, 2017).

On the other hand, both business and society agree on the point that the social development is the main concern of the state and the government is responsible for the public welfare. The state is the only power that can strategically estimate the volume and the directions of the necessary funding for the solution to the most important social concerns. That is why the center of the discussion about the role of the state in CSR is gradually shifting to the question of finding the right balance of interest and most appropriate forms of mutual cooperation of all parties concerned.

The question of the right balance of interest is one of the most acute. To make CSR programs more efficient business, the state and the society should understand their potential profits, costs and obligations. Additionally, it is important to remember that in real life it is impossible to divide the interests and costs of the parties.

The typical logical chain looks like the following. The main benefits for the business is the higher quality of the personnel. Internal social programs prevent the qualified workers from leaving the company, attract new experts and give new impulse for workers to increase the productivity without salary increase. It leads to the better image of the company, which makes it more interesting to potential investors. Simultaneously, external CSR programs contribute to the social stability at least on the local level. When the number of such companies reaches the certain level it leads to the higher social stability in general, and eventually results in higher investors' confidence in the country.

It is obvious that the scheme is a kind of an "ideal model". In real life there are there are a lot of spheres where the necessity and the profitability of CSR is not that evident. Traditionally, military complex is excluded from CSR logic. There are industries such as internet companies, scientific centers and other that do not produce any negative effect on the ecological or social environment. So, they do not feel obliged to pay additional costs on CSR.

In practice, we may say that now Russian own model of CSR is being formed, which is in line with the western understanding of CSR, however, this model has its clear-cut national features. Therefore, we will concentrate on these aspects.

Speaking about the directions of CSR in Russia, we can outline the following: environment issues, sustainable development, territories' social development, labour protection and human resources development.

It is interesting enough to compare briefly volumes and the scale of Russian and western CSR programs. An average figure for companies from Fortune 500 equals to $\$ 50$ million. Top five leaders spend on these goals more than $\$ 1$ billion a year. In Russia, as there is no standard procedure for mandatory publishing financial statements of CSR, it is difficult enough to assess the volume of investments in these programs. The data of the annual survey "Leaders of corporate charity" (a joint annual project initiated by Donors Forum, Vedomosti newspaper and $\mathrm{PwC}$ ) can be considered as the indirect measure of the scale of CSR-market. Fifty-two Russian and international companies operating in Russia took part in this survey in 2017. Only forty-six companies that participated in the survey 
revealed the information about their expenses on social support and charity. They spent more than 43.8 billion rubles on social support and charity (in 2015 fifty-four companies spent 19.9 billion rubles on the same needs). The largest volume of social investments for all years surveyed, i.e. 7 billion rubles, was recorded by PJSC MMC Norilsk Nickel [3].

Virtually, we may indicate four typical participants of CSR in Russia:

- Big companies from former Soviet monotowns;

- large strategically-oriented companies that work and have close links with the government;

- $\quad$ small and medium-sized companies;

- Philanthropists. They are not treated as a real participant of CSR, but at the same time, it is the most widespread form. Patronage and sponsorship help business become involved into socially oriented projects. In majority of cases, philanthropists are motivated more by their own interests rather than business interests.

The main difference between the Russian model of CSR and practices of western countries is that there is no definite goal and system in Russia. Since 2015 (the year when the United Nations General Assembly set Sustainable Development Goals), the majority of multinational companies in the world as well as Russian ones have started to adjust their CSR programs to these goals. However, taking into account the data given by RSPP, on the Russian market three quarters of the companies do not link their main goal with sustainable development goals, most organizations believe that they already make a contribution to the development of society, economy and environmental protection within the activity. For instance, only $35 \%$ of companies mention Sustainable Development Goals in their development strategies. Nevertheless, it is worth mentioning that both Russian companies and the Government develop in line with the indicated strategies. Therefore, if we compare the contents of the abovementioned national priority projects and the main goals of CSR programs, we may notice a clear correlation between them and such goals as Goal 3, Goal 8, Goal 11, Goals 13-15. According to the research, the obtained data confirm insufficient understanding by representatives of business of interrelation of commercial success and sustainable development, those opportunities that are available on the way of the movement to sustainable development goals when they are built in the business strategy. We hope that even in the absence of the well-defined aim by business to pursue goals of CSR programs and adhere to Sustainable Development Goals, Russia will be able to move forward to sustainable economic growth.

One more specific feature of the Russian model is the system of establishing relationship between business and the state with respect to CSR programs. Moreover, this model is not typical of western countries. On the one hand, the government urges business to launch socially oriented programs. In some cases, we may even use the term "pressure" that is put on business by authorities. As a result, CSR is not considered to be voluntary, but to some extent an obligatory condition of operating on certain markets and in certain regions. On the other hand, there is no support from the state. For instance, there are tax exemptions only for those companies, which do charity work only as a part of definite activity. What is more, companies are allowed to do some charity work using only net profit. Today there is an opportunity for them to reduce corporate tax from $18 \%$ to $13.5 \%$ on the regional level and get some VAT incentives. That is why there is a small advantage of charity over traditional CSR programs. The authors believe that establishing firm relationship between business and authorities with respect to this issue would lead to a considerable increase in efficiency of CSR programs both for business and for the whole country. 


\section{Conclusions}

In conclusion, we may say that taking care of interests of different partners, the management of a company efficiently fulfils its primary task connected with maximizing profits of shareholders. Such a strategy, in authors' opinion, makes closer two positions. Shareholders should not worry that their money may be controlled inefficiently until stakeholders' policy hampers such a strategy. Moreover, stakeholders' policy is beneficial to a company. First of all, the management of a company aims at building mutually beneficial relations with all its partners, who may explicitly or implicitly influence the thriving of a company. Then, such management creates favorable working conditions for workers who show willingness to work and climb the career ladder, paying attention to quality control of goods and services. As a result, the management in question brings more benefits than the management, which is interested only in maximizing profits.

Disregarding the concerns resulting from the current economic situation or left from the reform of the past, Russian big business is ready to realize full-scale CSR programs. Russian big companies already conduct numerous CSR programs on the internal and external levels. As the relations between the state and business are becoming more and more transparent and predictable, the attitude to corporate social responsibility will shift further from seeing it as an additional "social tax" to mutually beneficial well-balanced work to achieve stable social welfare.

Nowadays more and more businessmen and the society in Russia realize that in order to achieve sustainable economic growth it is necessary to have tight link and mutual contribution of business and the state. It is obvious that the private business activities, investment and innovation are major drivers of productivity, including economic growth and job creation; they create jobs, innovate, generate tax revenues. However, at the same time, the success of business depends on the health of the environment on local, national, and global levels, and helping the government to solve these problems such companies increase their competitiveness and profit.

\section{References}

1. M. S. Aßländer, J. Curbach, Business \& Society, 56(4), 617 (2017)

2. J. Bakan, The corporation: the pathological pursuit of Profit and power. London: (2005)

3. Corporate Social responsibility, industry specific supplement to the daily business newspaper RBC, 159(2883) (2018)

4. T. Donaldson, L. Preston, Academy of Management Review, 18(1), 65(1995)

5. Ecological report. "MMK. With care for the future", http://mmk.ru

6. G. Eweje, Introduction: Trends in Corporate Social Responsibility and Sustainability in emerging economies. Corporate social responsibility and sustainability: emerging trends in developing economies. Emerald Group Publishing Limited, 8, 3 (2014)

7. E. Feoktistova, G. Kopylova, M. Ozeryanskaya, M. Moskvina, N. Hofmann, D. Purtova, Compiled by authors, based on Russian Business and Sustainable Development Goals. Corporate practices collection (2018)

8. R. Freeman, J. Harrison, A. Wick, B. Parmar S. de Colle, Stakeholder theory: the state of the art, Cambridge: Cambridge University Press (2010)

9. M. Friedman, Capitalism and Freedom. Fortieth Anniversary, Chicago: University of Chicago Press (2009)

10. J. P. Gond, N. Kang, J. Moon, Economy and Society, 40(4), 640 (2011) 
11. C.M. Hoevring, S.E. Andersen A.E. Nielsen, Journal of Business Ethics, 152(3), 627 (2018)

12. P. S. Hofman, J. Moon, B. Wu, Corporate Social Business and Society, 56(5), 651 (2017)

13. Materials on the project «Creation of conditions for development corporate social responsibility business in the Pskov region», http://csdpr.ru/

14. J. Jahn, R. Brühl, Journal of Business Ethics, 153 (1), 41(2018)

15. J. Jung, H. Cho, Journal of Business and Retail Management Research, 11 (1), 7 (2016)

16. D. Matten, J. Moon, Academy of Management Review, 33(2), 404 (2008)

17. Report based on the survey of 2015 of managers working in the field of CRS in Central Europe, https://www2.deloitte.com

18. F. Perrini, A. Russo, A. Tencati, C. Vurro, Deconstructing the relationship between corporate social and financial performance.(2011)

19. A. G Scherer, G. Palazzo, Journal of Management Studies, 48(4), 899 (2011) 